\title{
COVID-19 in the operating room: a review of evolving safety protocols
}

\author{
Lakshmanan Prakash ${ }^{1}$, Shabir Ahmed Dhar ${ }^{2^{*}}$ and Muzaffar Mushtaq ${ }^{2}$
}

\begin{abstract}
Background: The COVID-19 pandemic has already infected more than 3 million people across the world. As the healthworkers man the frontlines, the best practices model is continuously evolving as literature concerning the Coronavirus develops.

Methods: A systematic review of the available literature was performed using the keyword terms "COVID-19", "Coronavirus", "surgeon", "health-care workers", "protection" and "Orthopaedic Surgery". All peer-reviewed articles we could find were considered. Randomized controlled trials (RCTs), prospective trials and retrospective studies, as well as reviews and case reports, were included in this systematic review.

Results: Even though surgical specialties including orthopedics are on the relative sidelines of the management of this pandemic but best practices models are inevitably developed for surgical specialties. The algorithm of postpone, delay, and operate only when life-threatening conditions exist is going to be useful up to a point.

Conclusion: The surgical staff needs to keep abreast of the latest literature concerning safety measures to be taken during surgical procedures. Review articles can go some distance in helping in this educational process. This knowledge must evolve as new information comes to light.
\end{abstract}

Keywords: COVID-19, Coronavirus, Surgeon, Health care workers, Protection, Orthopaedic surgery

\section{Introduction}

The COVID 19 was labeled as a Pandemic on 11 March 2020 [1]. At the time of writing nearly 4 million people have been affected. The clinical spectrum of this disease is known to be very heterogeneous [2]. As the number of cases increases worldwide, the possibility of having to operate cases with the coronavirus infection is increasing. This will happen despite the current recommendations of operating only the emergent cases [3]. Cheney C in his write up on March 27 mentions that according to the guidelines of the centers for disease control and prevention elective surgery during the pandemic should be delayed [4]. These recommendations were made with the foresight of infrastructure and staff shortages.

\footnotetext{
* Correspondence: shabirdhar@yahoo.co.in

${ }^{2}$ SKIMS MC Bemina, Srinagar, Kashmir, India

Full list of author information is available at the end of the article
}

However, as the pandemic progresses two things have to be kept in mind by the health care authorities [1]. The increasing likelihood of COVID positive emergency cases presenting for surgical intervention.

The inevitability of having to restart elective procedures at some point in time. This is likely to happen whilst the pandemic is still around in some form. With the proven contagious properties of the virus and the relatively newer concept of the viral load, surgical safety measures need to be discussed as extensively as possible [2]. Gleaning from trauma literature it is seen that there is an increased likelihood of contracting COVID-19 in hospitals. Thousands of healthcare providers have been infected with COVID-19 despite their adherence to infection control measures [5].

C C The Author(s). 2020 Open Access This article is licensed under a Creative Commons Attribution 4.0 International License, which permits use, sharing, adaptation, distribution and reproduction in any medium or format, as long as you give appropriate credit to the original author(s) and the source, provide a link to the Creative Commons licence, and indicate if changes were made. The images or other third party material in this article are included in the article's Creative Commons licence, unless indicated otherwise in a credit line to the material. If material is not included in the article's Creative Commons licence and your intended use is not permitted by statutory regulation or exceeds the permitted use, you will need to obtain permission directly from the copyright holder. To view a copy of this licence, visit http://creativecommons.org/licenses/by/4.0/ The Creative Commons Public Domain Dedication waiver (http://creativecommons.org/publicdomain/zero/1.0/) applies to the data made available in this article, unless otherwise stated in a credit line to the data. 
This paper attempts to look at the current relatively scarce literature and answer some questions about the readiness and methods required for conducting safe surgery especially orthopedic intervention during the COVID-19 pandemic. The evolving literature must be published and read worldwide as COVID-19 is an occupational hazard to surgeons, health care workers, and their families.

\section{Material and method}

A systematic review of the available literature was performed using the keyword terms "COVID-19", "Coronavirus", "surgeon", "health-care workers", "protection" and "Orthopaedic Surgery". All peer-reviewed articles we could find were considered. Randomized controlled trials (RCTs), prospective trials and retrospective studies, as well as reviews and case reports, were included in this systematic review.

\section{Discussion}

The current COVID-19 pandemic underlines the importance of careful and sensible utilization of financial and human resources. Preserving manpower is vital. A definite attempt should be made to minimize infection amongst surgeons and specialized professionals. While it is true that the surgical specialists are not at the forefront of managing the pandemic but two points have to be kept in mind vis a vis these specialists [6].

1. The likelihood of getting infected in the confines of the operation theatres is disproportionately high.

2. The training period of a surgeon is quite long. Replacing the surgeon is not a straightforward task.

The pandemic preparedness and literature evolution have mainly been on the Personal Protective Equipment (PPE) and Intensive Care Unit (ICU) areas. Not much has been written on the risks involved, methods and precautions required for an orthopedic surgeon and his operating room personnel whilst carrying out surgical procedures within the theatre.

Mild cases of COVID-19 have been found to have an early viral clearance, with $90 \%$ of these patients repeatedly testing negative on RT-PCR by day 10 post-onset. By contrast, all severe cases still tested positive at or beyond day 10 post-onset. Overall, our data indicate that, similar to SARS in 2002-03, patients with severe COVID-19 tend to have a high viral load and a long virus-shedding period. This finding suggests that the viral load of SARS-CoV-2 might be a useful marker for assessing disease severity and prognosis [2]. This concept of viral load is especially important for the operating surgeon.
Coccolini et al. believe that all known or suspected COVID-19 positive patients requiring surgical intervention must be treated as positive until proven otherwise to minimize infection spread [6]. However, it is preferable to order immediate SARS-CoV-2RT-PCR assay if a patient is being admitted and especially before surgery and possible intubation.

The surgeon also has to factor in staff sickness, reduced supply of surgical materials, alternate use of surgical facilities, and relatively lower availability of anaesthesiologists because of their additional intensive care loads [1].

Lei et al. studied 34 patients who underwent elective surgeries during the incubation period of COVID-19 at 3 hospitals. All their patients developed COVID-19 pneumonia shortly after surgery. $44.1 \%$ of patients needed intensive care postoperatively and the mortality rate was 20.5\% [7]. Five of these surgeries were conducted in orthopedic specialist areas. The correlation is explained by the probable lowering of cell-mediated immunity after surgery which is vital for defense against viral infections [8]. Similar to the Middle East Respiratory Syndrome Coronavirus (MERS-CoV) infection, the Severe acute respiratory syndrome-related coronavirus (SARS-CoV) infected lung could induce and increase the amount of macrophage and neutrophil infiltration and increase the levels of pro-inflammatory cytokines and chemokines [9-11].

From the literature mentioned, it is clear that a COVID-19 patient undergoing surgery is at a higher risk of complications. Even though scientific literature on the surgeons getting affected during surgery is not available, it is important to view the media reports with more seriousness than usual [12].

\section{When to operate?}

The SAGES and EAES recommendations regarding surgical response to COVID-19 mention that services should be rationed [13]. They have included the following points, amongst others, in the rationing

1. All elective surgical and endoscopic cases should be postponed at the current time.

2. All non-essential hospital or office staff should be allowed to stay home and telework.

The procedural considerations laid down in the same paper include

1. It is strongly recommended however, that consideration be given to the possibility of viral contamination to staff during surgery either open, laparoscopic, or robotic and that protective 
measures are strictly employed for OR staff safety and to maintain a functioning workforce.

2. For MIS procedures, the use of devices to filter released $\mathrm{CO} 2$ for aerosolized particles should be strongly considered.

3. There may be an enhanced risk of viral exposure to proceduralists.

The surgical team needs to be updated as to the latest protocols being used to ensure increased safety within the operation theatres to prevent the spread of the coronavirus outside the theatre and disease amongst the theatre personnel.

Philip F. Stahel published an editorial in which he divided elective procedures into "essential", which bear an increased risk of adverse outcomes if surgery is delayed indefinitely, "non-essential" or "discretionary", in which the results are not time-sensitive to surgery and "equivocal" which don't fall clearly into one or the other category.

He proposed an decision-making algorithm (Fig. 1) for deciding whether and when to proceed with an elective surgery, based on surgical indications and predicted requirement of critical resources, including blood product transfusions, estimated length of hospital stay, and the possible requirement for post-operative ventilation and ICU care [14].

\section{Where to operate?}

$\mathrm{Ti}$ et al. have written that a relatively isolated theater with separate access and a negative pressure environment should be designated for such patients [15]. The negative pressure method is restricted in the anteroom and the induction room. The scrub area and the main operating room have positive pressures. The main operating room should have more than 25 air exchange cycles per hour. According to them understanding the airflow within the operation theatre is crucial to minimizing the risk of infection. Operating rooms are usually designed to have positive pressure to prevent intraoperative contamination. Coronavirus is $125 \mathrm{~nm}$ in diameter and a high proportion of particles [up to 100\%] are captured by high-efficiency particulate air (HEPA) filters. This may be combined with the aforementioned high-frequency air exchanges to reduce the chance of virus dissemination $[1,16,17]$.

Pinto et al. recommend that the operative complex be divided into 5 zones as shown in Table 1. This ensures an orderly process reducing dissemination.

A route to minimize exposure and contact between triage to induction room, $\mathrm{OR}$ and then to recovery rooms should be frequently cleaned and disinfected [18].

\section{The surgeon and the theatre staff}

The surgeons scrubbing routine has to change when entering the corona designated theatres. In Zone 1 a disposable surgical scrub suit, surgical boots, waterproof boot and a waterproof apron should be donned. Surgical hand preparation should also be done with water and chlorhexidine gluconate [1]. The surgeon should use either N95 or FFP 2 masks as recommended by the centers of disease control and prevention. They are effective for viruses including the coronavirus [19]. Powered airpurifying respirators [PAPR] is preferred for longer operations. Double surgical masks should be avoided especially in aerosolized blood generating procedures (Table 2).

Eye protection equipment is also important during aerosol-generating procedures [18]. Full face shield or goggles are recommended.

In zone 2 either a surgical spacesuit or the second layer of sterile protective garments should be used. A surgical shield is also desirable. An aqueous alcohol solution is used for scrubbing. The first pair of gloves are donned. This should be followed by a sterile surgical scrub suit and second pair of gloves [1].

Surgical gowns (AAMI) [association of the advancement of medical instrumentation] - Level III (typically those found in operating rooms) or Coveralls should be prioritized for surgical and aerosolized-blood generating procedures. Surgical caps should be used as per protocol, but surgical hood with ties should be used for the head and the neck for aerosol-generating procedures [18]. Shoes or booties should be fluid resistant and double high cuffed surgical gloves are preferable.

After the surgery the staff exits through zone 4 where doffing is done. in zone 5 the scrub suit is removed and bathing is done.

Strict and frequent screening of the segregated OR staff is mandatory. Members of the segregated or exposed staff should immediately report any signs of illness and must be taken off duty immediately. Besides, all contact events between patients and staff must be recorded so that contact tracing and infection control measures can be implemented quickly, in case any member of segregated staff tests positive.

\section{Anesthesia considerations}

The most experienced anaesthesiologist should intubate the patients. Ti et al. also recommended that the same operation theatre be used along with the same anesthesia machine for COVID cases. A heat and moisture exchanger (HME) filter is used on the expiratory limb of the circuit. The soda-lime and filters are exchanged after each case. Disposable airway equipment is to be used. The airway should be secured with the method which has the highest chance of first-time success especially video-laryngoscope [20]. Airway manipulation, face mask ventilation, and open airway suction 


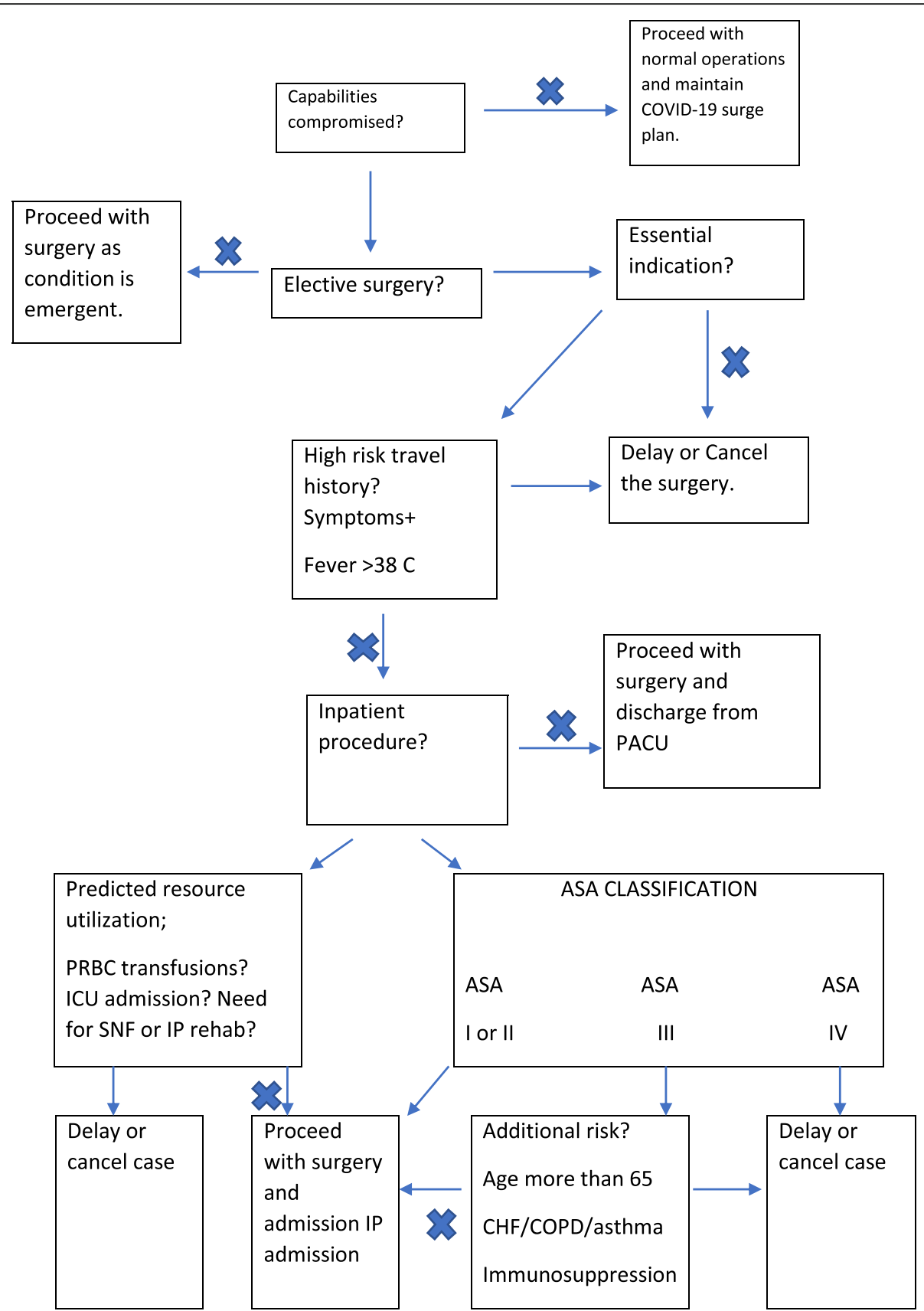

Fig. 1 The decision-making algorithm for risk-stratification of elective surgical procedures. It is based on the underlying surgical indication and predicted resource utilization during the current COVID-19 pandemic [14]. Abbreviations: ASA, American Society of Anesthesiologists; CHF, chronic heart failure; COPD, chronic obstructive pulmonary disease; COVID, corona virus disease; ICU, intensive care unit; IP, inpatient; PACU, postanesthesia care unit; PRBC, packed red blood cells; SNF, skilled nursing facility

should be minimized. Bag mask ventilation should also be avoided. If a patient is transferred directly from the intensive care unit, a dedicated transport ventilator should be utilized. To reduce aerosolization risks, the gas flow should be turned off and the endotracheal tube clamped with forceps when switching from the portable device to the OR ventilator [15]. Regional anesthesia is preferable. Nasal Oxygen should be administered under the surgical mask. Antiemetics should be used to reduce post-operative retching.

If the patient is already in an ICU, Firstenberg et al. recommended intubation in the negative flow ICU prior to transport to the OR by the attending intensivist, while using appropriate precautions including N95 mask or PPE, gown, eye protection and hair cover, to avoid exposure to the anaesthesia team [21]. 
Table 1 Zones of the operation theatre

Zone 1: Entry dressing room, where the basic PPE is donned
Zone 2: Anteroom, where the disinfection and surgical dressing take
place
Zone 3: OR (COVID-19 room)
Zone 4: Exit room, where the PPE is removed
Zone 5: Exit dressing room, where the staff showers

\section{How to transfer}

The transfer from the ward to the OR will be done by the ward nurses in full personal protective equipment (PPE) (Table 2) including a well-fitting N95 mask, goggles, or face shield, splash-resistant gown, and boot covers. For patients coming from the ICU, a dedicated transport ventilator is used. To avoid aerosolization, the gas flow is turned off and the endotracheal tube clamped with forceps [15]. Fisrtenberg et al. used a portable travel ventilator with a High-Efficiency Particulate Air (HEPA) filter placed between the endotracheal tube and the circuit and a second HEPA filter between the circuit and ventilator. They advised that two members of hospital security escort the transporting team to ensure elevator availability, open doors, and to minimize the risk of accidental contact with others during the transport [21].

While Li TK et al. have recommended an operation theater at the corner of the operation theatre complex with separate access, Coccolini et al. recommend an OT closest to the entrance of the complex [5, 15]. This probably depends on the architecture of the theatre complex as Pinto et al. mention a satellite position of the operation theatre [1]. They also recommend a 5room complex.

Transfer routes should be as short as possible and precisely planned, with the same transport personnel throughout the shifting process [6]. We feel that this shall again vary depending on theater design and layout.

Table 2 Personal protection equipment [5]

Personal protection equipment
FFP2 facial mask
FFP3 facial mask (in case of maneuvers at high risk of generating
Disposable long sleeve waterproof coats, gowns, or Tyvek suits
Disposable double pair of nitrile gloves
Protective goggles or visors
Disposable head caps
Disposable long shoe covers
Alcoholic hand hygiene solution
FFP Filtering face piece

FFP2 facial mask

FFP3 facial mask (in case of maneuvers at high risk of generating aerosolized particles)

Disposable double pair of nitrile gloves

Protective goggles or visors

Disposable head caps

Disposable long shoe covers

FFP Filtering face piece

\section{Intraoperative protocol}

Air exchange cycles should be increased whenever possible to $\geq 25$ exchanges/h between surgeries [22, 23]. Even though no data currently exist on COVID-19 viral load in bodily fluids or tissue samples, extreme care is mandatory. Surgeons and personnel not needed for intubation should remain outside the operating room until anesthesia induction and intubation are completed for patients with or suspected of having COVID-19 infection [24].

Orthopedic surgery offers specific challenges and difficulties. Hart mentions that with the asymptomatic patients being quite large, the operation theatre might be a viral lab in a wind tunnel. Writing about orthopedic surgery he mentions that power tools, hammers, and other instruments spread a lot of material around. Even though we do not know about the concentration of COVID19 in blood and muscle, research into the airborne transmission of SARS and MERS makes it plausible that transmission is likely [25]. A recent Canadian study described low-fidelity simulation training to evolve the modified PPE used for aerosolgenerating procedures of suspected/confirmed COVID19 patients and assess sites of contamination [26]. The Spread of the aerosolized respiratory secretions and contamination sites were visualized with a commercial powder product and ultraviolet light. They demonstrated a significant amount of contamination on the provider's neck, the base of the wrist, and their lower pants and shoes. Aerosols have been shown to spread from 5 to 7 $\mathrm{m}$ during orthopedic surgery. Hip replacement surgery can cause a spread of aerosol from 8 to $9 \mathrm{~m}[27,28]$.

Minimum personnel should be placed in the operating room. Firstenberg et al. kept two runners were outside of the OR. Only minimum required supplies were opened in the procedure room, and whenever required the runners fetched the additional supplies needed for the case which were placed on a cart in the containment room and transported into the OR only when the outside door was shut. No additional phones or breaks/ changes in staff should be allowed [21].

A smoke evacuator should be used when electrocautery is to be used. Particles in surgical smoke have been demonstrated to contain a variety of toxic and virulent materials thought to be capable of infecting those who inhale them, with case reports of doctors contracting rare papillomavirus when surgical smoke exposure was suspected to be the source [29]. Hence electrosurgery should be minimized or excluded. Bulb syringes should be used for lavage.

In trauma and orthopedic surgical procedures, the use of power tools, such as electrocautery, bone saws, reamers, and drills, releases aerosols [15], increasing the risk of virus spread. As such, their use should be reduced 
to the minimum and the power settings should be as low as possible [30]. Some possible complications include the formation of a viral biofilm.

Disposable medical equipment should be used. A sharp injury should be avoided to the PPE. All body fluids, blood, secretions, pathological specimens should be disposed of in double bags that are sealed. Any specimens taken should be placed into a biohazard bag inside the $\mathrm{OR}$ and subsequently placed in another biohazard bag in the containment room before being sent to the lab being properly labeled, for example as "Covid positive" or "suspected covid" [21].

COVID-19 is presumed to spread directly via infectious respiratory droplets and close contact (since SARSCoV-2 cannot survive without carrier) [12] However, these transmission modes do not explain all cases. Recent data has shown that COVID-19 might survive and be transmitted indirectly from virus contamination of common surfaces and objects after virus aerosolization in a confined space with infected individuals [31]. The incubation period for COVID-19 is approximately 4 days and studies suggest it may range anywhere from 2 to 14 days. Individuals with respiratory sickness should not be allowed to donate blood due to a lack of definitive evidence of blood transmission of COVID-19 [3234]. Theoretically, viremia in patients with asymptomatic or confirmed COVID-19 patients could pose a risk of transmissibility to the orthopedic team during aerosolized-blood generating procedures.

The theatre is to be disinfected between surgeries. But the disinfecting personnel should enter the theatre only after enough air changes have occurred to remove infectious particles [18]. If possible, no other surgery should be carried out in the same OR for the day, and theatre disinfected with UV light. The instruments sent to the sterilization unit must be labeled and the staff in the unit must be made aware of the covid status of the case, and must handle the instruments while wearing a full PPE [21].

The risk in theatres might be more in resourceconstrained settings. Jain et al. mention that the emergence of COVID-19 has impacted orthopedic surgery worldwide. India, with its large population and limited health resources, will be overwrought over the coming days due to the number of cases of critically ill patients with COVID-19 [35].

Guo X et al. showed that 26 orthopedic surgeons got infected with COVID-19 in 3 hospitals in Wuhan. This highlights the fact that despite being a surgical specialty, the risk is quite high [36].

It is important to understand that aerosols can be generated either by surgery or by the respiration of the patient within the theatre [37, 38]. ENT, Neurosurgery, and Opthalmology surgeons are at risk from both types of aerosols while orthopedic surgeons are exposed to high levels of surgical aerosol but a lower risk of respiratory aerosol.

\section{Recovery}

Surgeries that take longer time are likely to have more postoperative complications in a routine setting. These complications must be differentiated from COVID 19. Surgeons, nurses, and medical staff share equal responsibility for postoperative management, particularly in monitoring the patients' families and visitors to ensure strict adherence to the pandemic emergency system. When possible, it is important to limit visitors as much as possible. Most hospitals have recently discontinued visitation by anyone [18]. Lei et al. showed significantly higher COVID related complications in these cases [7].

Massey e al recommended additional measures including physical Distancing and use of emerging technologies such as inpatient telemedicine and online file sharing applications to enable orthopedic programs to still function, while attempting to protect medical staff and patients from COVID-19 spread [39].

Cohen et al. suggest championing an alternative solution whereby we as a medical community become proactive rather than reactive, adopting a conservative yet balanced plan to protect both the patient and the health-care team. When faced with a biologically plausible concern that could infer serious harm, we are obligated to act with an abundance of caution, examining and questioning our standard practices [40].

It is acknowledged that, during the coronavirus pandemic, surgeons and patients will have difficult choices to make about management options for a wide variety of injuries and urgent conditions. They will need to balance optimum treatment of a patient's injury or condition against clinical safety and resources [41].

The orthopedic community is continuing to develop strategies to deliver a safe musculoskeletal skeletal service at this difficult time, while many members of the orthopedic workforce move to the front line [42].

In the end, we must admit that however thorough our search through the literature maybe, in the current trend of evolving guidelines and protocols about surgical care of covid-19 patients, any meticulously drafted treatise will quickly become obsolete if not updated along. Here we list a few resources that we find immensely helpful for surgeons and orthopedic surgeons to keep themselves aware of the best practice guidelines issued from time to time by these reputed public health organizations:

National Institute for Health and Care Excellence (UK): https://www.nice.org.uk/guidance/health-and-socialcare-delivery/surgical-care 
World Health Organization: https://www.who.int/ surgery/publications/immesc_best_practice/en/ Centre for Disease Control and Prevention: https:// www.cdc.gov/coronavirus/2019-ncov/hcp/ preparedness-checklists.html Royal College of Surgeons, England: https://www. rcseng.ac.uk/standards-and-research/standards-andguidance/good-practice-guides/coronavirus/covid-19good-practice-for-surgeons-and-surgical-teams/ American College of Surgeons: https://www.facs.org/ covid-19/checklist

American Association of Orthopaedic Surgeons: https://www.aaos.org/about/covid-19-information-forour-members/guidance-for-elective-surgery/ AO foundation: https://www.aofoundation.org/whatwe-do/covid-19-resources-for-surgeons

\section{Conclusion}

The surgical staff needs to keep abreast of the latest literature concerning safety measures to be taken during surgical procedures. Review articles can go some distance in helping in this educational process. This knowledge must evolve as new information comes to light. Infection or death of sub-specialized staff must be minimized to preserve the ability to face surgical emergencies and associated activities that will continue to occur or perhaps increase during a mass casualty incident.

\section{Core tip}

It is important for surgical specialists to stay up to date with the latest information concerning safety measures while conducting surgeries. The evolution of literature should be closely followed so that the best practices are instituted and upgraded.

\section{Abbreviations \\ RCT: Randomised controlled trial; COVID: Corona virus disease; PPE: Personal protection equipment; ICU: Intensive care unit; RT-PCR: Reverse transcription polymerase chain reaction; SARS: Severe acute respiratory syndrome; MERS: Middle east respiratory syndrome; CoV: Corona virus; SAGES: Society of American gastrointestinal and endoscopic surgeons; EAES: European association for Endoscopic Surgery; HEPA: High efficiency particulate air; FFP: Filtering face piece; PAPR: Powered air purifying respirator; AAMI: Association of the advancement of medical instruments; HME: Heat and moisture exchanger; PPE: Personal protective equipment}

\section{Availability of data and material}

The data collected for this review article are available by the corresponding author upon request.

\section{Authors' contributions}

LP contributed to the formulation of the idea and collected data. SAD wrote and reviewed the article. MM helped with the revision. The author(s) read and approved the final manuscript.

\section{Funding}

The authors received no funding for this article.

Ethics approval and consent to participate Not Applicable.

\section{Consent for publication}

Not Applicable.

\section{Competing interests}

The authors declare that they have no competing or conflicting interests with any of the specific entities mentioned in this manuscript.

\section{Author details}

${ }^{1}$ Institute of Special Orthopaedics, Palakkad, Kerala, India. ${ }^{2}$ SKIMS MC Bemina, Srinagar, Kashmir, India.

Received: 20 May 2020 Accepted: 6 July 2020

Published online: 20 July 2020

\section{References}

1. Pinto RP, Ricardo MD, Sousa R, Olivier A. The orthopedic forum. Preparing to perform trauma and orthopedic surgery on patients with COVID-19. J Bone Joint Surg Am. 2020;102(11):946-50

2. Guan WJ, Ni ZY, Hu Y. Clinical characteristics of coronavirus disease 2019 in China. N Engl J Med. 2020;382(18):1708-20.

3. NHS. Clinical guide for the management of trauma and orthopaedic patients during the coronavirus pandemic. 2020. https://www.england.nhs. uk/coronavirus/wpcontent/uploads/sites/52/2020/03/specialty-guideorthopaedic-trauma-and-coronavirus-v1-16-march2020.pdf. Accessed 31 Mar 2020

4. Cheney C. Corona virus; follow 7 overarching principles for delaying elective surgery. 2020. Health Leaders. https://www.healthleadersmedia.com/clinicalcare/coronavirus-follow-7-overarching-principles-delaying-elective-surgery.

5. Wang D, Hu B, Hu C, Zhu F, Liu X, Zhang J, Wang B, Xiang H, Cheng Z, Xiong Y, Zhao Y, Li Y, Wang X, Peng Z. Clinical characteristics of 138 hospitalized patients with 2019 novel coronavirus-infected pneumonia in Wuhan, China. JAMA. 2020;323(11):1061-9.

6. Coccolini F, Perrone G, Chiarugi M, Di Marzo F, Ansaloni L, Scandroglio I, Marini P, Zago M, De Paolis P, Forfori F, Agresta F, Puzziello A, D'Ugo D, Bignami E, Bellini V, Vitali P, Petrini F, Pifferi B, Corradi F, Tarasconi A, et al. Surgery in COVID-19 patients: operational directives. World J Emerg Surg. 2020;15:25 Published online 2020 Apr 7

7. Lei S, Jiang F, Su W, Chen C, Chen J, Mei W, Zhan LY, Jia Y, Zhang L, Liu D, Xia ZY, Xia Z. Clinical characteristics and outcomes of patients undergoing surgeries during the incubation period of COVID-19 infection. EClinicalMedicine. 2020;21:100331 [published online ahead of print, 2020 Apr 5].

8. Amodeo G, Bugada D, Franchi S, Moschetti G, Grimaldi S, Panerai A, Allegri M, Sacerdote P. Immune function after major surgical interventions: the effect of postoperative pain treatment. J Pain Res. 2018;11:1297-305 Published 2018 Jul 10.

9. Zhou J, Chu H, Li C, Wong BH, Cheng ZS, Poon VK, Sun T, Lau CC, Wong KK, Chan JY, Chan JF, To KK, Chan KH, Zheng BJ, Yuen KY. Active replication of Middle East respiratory syndrome coronavirus and aberrant induction of inflammatory cytokines and chemokines in human macrophages: implications for pathogenesis. J Infect Dis. 2014;209(9):1331-42.

10. Chien JY, Hsueh PR, Cheng WC, Yu CJ, Yang PC. Temporal changes in cytokine/chemokine profiles and pulmonary involvement in severe acute respiratory syndrome. Respirology. 2006;11(6):715-22.

11. Law HK, Cheung CY, Ng HY, Sia SF, Chan YO, Luk W, Nicholls JM, Peiris JS, Lau YL. Chemokine up-regulation in SARS-coronavirus-infected, monocytederived human dendritic cells. Blood. 2005;106(7):2366-74.

12. Neurosurgeon dies of COVID-19. Fatalities mount to 16 in Tamil Nadu. 2020 https://www.deccanherald.com/national/south/neurosurgeon-dies-ofcovid-19-fatalities-mount-to-16-in-tamil-nadu-827532.html.

13. Aurora Pryor. SAGES and EAES recommendations regarding surgical response to COVID-19 crisis. 2020. Released 3/30/2020.

14. Stahel PF. How to risk-stratify elective surgery during the COVID-19 pandemic? Patient Saf Surg. 2020;14:8.

15. Ti KL, Ang LS, Foong TW, Ng BSW. What do we do when a COVID 19 patient needs an operation; operating room preparation and guidance. Can J Anaesth. 2020;67(6):756-8.

16. Fehr AR, Perlman S. Coronaviruses: an overview of their replication and pathogenesis. Methods Mol Biol. 2015;1282:1-23.

17. Perry $J$, Aqui $J H$, Vijayakimar R. Submicron and nanoparticulate matter removal by HEPA-rated media filters and packed beds of granular materials. 
NASA Technical Reports Server. 2016. https://ntrs.nasa.gov/archive/nasa/casi. ntrs.nasa.gov/20170005166.pdf. Accessed 31 Mar 2020.

18. Awad ME, Rumley JCL, Vasquez JA, Devine JG. Perioperative considerations in urgent surgical care of suspected and confirmed COVIF-19 Orthopaedic patients. Operating room protocols and recommendations in the current COVID-19 pandemic. J Am Acad Orthop Surg. 2020;28(11):451-63.

19. U.S. Centers for Disease Control and Prevention (CDC). Coronavirus (COVID19). 2020. https://www.cdc.gov/coronavirus/2019-ncov/index.html. Accessed 25 Mar 2020.

20. Peng PW, Ho PL, Hota SS. Outbreak of a new coronavirus: what anaesthetists should know. Br J Anaesth. 2020;124(5):497-501.

21. Firstenberg MS, Libby M, Ochs M, Hanna J, Mangino JE, Forrester J. Isolation protocol for a COVID-2019 patient requiring emergent surgical intervention: case presentation. Patient Saf Surg. 2020;14:15.

22. Wong J, Goh QY, Tan Z, Lie SA, Tay YC, Ng SY, Soh CR. Preparing for a COVID-19 pandemic: a review of operating room outbreak response measures in a large tertiary hospital in Singapore. Se préparer pour la pandémie de COVID-19: revue des moyens déployés dans un bloc opératoire d'un grand hôpital tertiaire au Singapour. Can J Anaesth. 2020; 67(6):732-45.

23. Chow $T$, Yang $X Y$. Ventilation performance in operating theatres against airborne infection: review of research activities and practical guidance. J Hosp Infect. 2004;56(2):85-92.

24. COVID-19; Considerations for optimum surgeon protection before, during, and after operation. American college of surgeons. https://www.facs.org/ covid-19/clinical-guidance/surgeon-protection. Updated April 12020.

25. Raphael T. Why surgeons don't want to operate right now. Bloomberg Opinion. 2020. https://www.bloomberg.com/opinion/articles/2020-03-24/ the-coronavirus-crisis-is-putting-surgeons-at-risk-too.

26. Lockhart SL, Naidu JJ, Badh CS, Duggan LV. Simulation as a tool for assessing and evolving your current personal protective equipment: lessons learned during the coronavirus disease (COVID-19) pandemic. Can J Anaesth. 2020;67(7):895-6.

27. Nogler M, Lass-Florl C, Wimmer C, Bach C, Kaufmann C, Ogon M. Aerosols produced by high-speed cutters in cervical spine surgery: extent of environmental contamination. Eur Spine J. 2001;10(4):274-7.

28. Nogler M, Lass-Florl C, Wimmer C, Mayr E, Bach C, Ogon M. Contamination during removal of cement in revision hip arthroplasty. A cadaver study using ultrasound and highspeed cutters. J Bone Joint Surg (Br). 2003;85(3):436-9.

29. Zheng $\mathrm{MH}$, Boni L, Fingerhut $\mathrm{A}$. Minimally invasive surgery and the novel coronavirus outbreak: lessons learned in China and Italy. Ann Surg. 2020, 2020. https://doi.org/10.1097/SLA.0000000000003924 [published online ahead of print, 2020 Mar 26].

30. Yeh HC, Turner RS, Jones RK, Muggenburg BA, Lundgren DL, Smith JP. Characterization of aerosols produced during surgical procedures in hospitals. Aerosol Sci Technol. 1995;22(2):151-61.

31. Cai J, Sun W, Huang J, Gamber M, Wu J, He G. Indirect virus transmission in cluster of COVID-19 cases, Wenzhou, China, 2020. Emerg Infect Dis. 2020; 26(6):1343-5.

32. Li Q, Guan X, Wu P, Wang X, Zhou L, Tong Y, Ren R, Leung K, Lau E, Wong JY, Xing X, Xiang N, Wu Y, Li C, Chen Q, Li D, Liu T, Zhao J, Liu M, Tu W, et al. Early transmission dynamics in Wuhan, China, of novel coronavirusinfected pneumonia. N Engl J Med. 2020;382(13):1199-207.

33. Chan JF, Yuan S, Kok KH, To KK, Chu H, Yang J, Xing F, Liu J, Yip CC, Poon RW, Tsoi HW, Lo SK, Chan KH, Poon VK, Chan WM, Ip JD, Cai JP, Cheng VC, Chen $\mathrm{H}$, Hui CK, et al. A familial cluster of pneumonia associated with the 2019 novel coronavirus indicating person-to-person transmission: a study of a family cluster. Lancet (Lond Engl). 2020;395(10223):514-23.

34. Chen N, Zhou M, Dong X, Qu J, Gong F, Han Y, Qiu Y, Wang J, Liu Y, Wei Y, Xia J, Yu T, Zhang X, Zhang L. Epidemiological and clinical characteristics of 99 cases of 2019 novel coronavirus pneumonia in Wuhan, China: a descriptive study. Lancet (Lond Engl). 2020;395(10223):507-13.

35. Jain VK, Vaishya R. COVID-19 and orthopaedic surgeons: the Indian scenario. Trop Dr. 2020;50(2):108-10.

36. Guo X, Wang J, Hu D, Wu L, Gu L, Wang Y. Survey of COVID-19 disease among orthopaedic surgeons in Wuhan, People's Republic of China. J Bone Joint Surg Am. 2020;102(10):847-54.

37. Hirschmann MT, Hart A, Henckel J, Sadoghi P, Sell R, Mouton C. COVID-19 coronavirus: recommended personal protective equipment for the orthopaedic and trauma surgeon. Knee Surg Sports Traumatol Arthrosc. 2020;28(6):1690-8
38. Howard RA, Lathrop GW, Powell N. Sterile field contamination from powered air-purifying respirators (PAPRs) versus contamination from surgical masks. Am J Infect Control. 2020;48(2):153-6.

39. Massey PA, McClary K, Zhang AS, Savoie FH, Barton SR. Orthopaedic surgical selection and inpatient paradigms during the coronavirus COVID-19 pandemic. J Am Acad Orthop Surg. 2020;28(11):436-50.

40. Cohen SL, Liu G, Abrao M, Smart N, Todd H. Perspectives on surgery in the time of COVID-19. Safety First. J Minim Invasive Gynecol. 2020; Pre-proof copy, ahead of print.

41. BOA, BSCOS, BSSH. Management of patients with urgent orthopaedic conditions and trauma during the coronavirus pandemic. 2020. https:// www.boa.ac.uk/resources/covid-19-boasts-combined.html.

42. Morgan C, Ahluwalia AK, Aframian A, Li L, Sun SNM. The impact of the novel coronavirus on trauma and orthopaedics in the UK. Br J Hosp Med (Lond). 2020;81(4):1-6.

\section{Publisher's Note}

Springer Nature remains neutral with regard to jurisdictional claims in published maps and institutional affiliations.

Ready to submit your research? Choose BMC and benefit from:

- fast, convenient online submission

- thorough peer review by experienced researchers in your field

- rapid publication on acceptance

- support for research data, including large and complex data types

- gold Open Access which fosters wider collaboration and increased citations

- maximum visibility for your research: over $100 \mathrm{M}$ website views per year

At $\mathrm{BMC}$, research is always in progress.

Learn more biomedcentral.com/submissions 